Supplement of Biogeosciences Discuss., 12, 6821-6861, 2015

http://www.biogeosciences-discuss.net/12/6821/2015/

doi:10.5194/bgd-12-6821-2015-supplement

(C) Author(s) 2015. CC Attribution 3.0 License.

(c) (i)

Supplement of

\title{
Influence of tree size, taxonomy, and edaphic conditions on heart rot in mixed-dipterocarp Bornean rainforests: implications for aboveground biomass estimates
}

\author{
K. D. Heineman et al.
}

Correspondence to: K. D. Heineman (kheineman@life.illinois.edu) 
Table S1. Soil properties measured in the Central Sarawak drilling and felling data and used to construct soil PC axes, with their range of values observed across sample plots and loadings on the first four PC axes in the principle components analysis (see main text for details). Topsoil samples represent the top $10 \mathrm{~cm}$ of the soil profile, and subsoil samples were collected from $45-$ $55 \mathrm{~cm}$ in depth. The variables with the five largest rotation coefficients for each PC axis are highlighted in bold. Soil concentrations are expressed in units of milliequivalents per $100 \mathrm{~g}$ of soil (me\%), parts per million (ppm), or percent dry weight (\%).

Range $\quad$ PC Axis Loadings

Soil

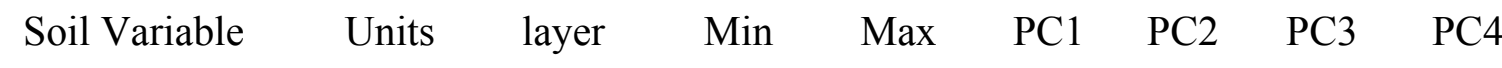

\begin{tabular}{lllcccccc}
\hline \hline CEC & me\% & Subsoil & 1.6 & 17 & 0.17 & 0.20 & 0.23 & 0.10 \\
CEC & me\% & Topsoil & 2.03 & 28.79 & 0.09 & 0.12 & $\mathbf{0 . 2 6}$ & $\mathbf{0 . 3 6}$ \\
Clay & $\%$ & Subsoil & 8.8 & 57.5 & $\mathbf{0 . 2 7}$ & -0.12 & 0.15 & -0.08 \\
Clay & $\%$ & Topsoil & 4.1 & 54.6 & $\mathbf{0 . 2 7}$ & -0.15 & 0.12 & -0.06 \\
Fe/Al sesquioxides & $\%$ & Subsoil & 0.71 & 29.89 & 0.26 & -0.10 & 0.05 & -0.10 \\
Fe/Al sesquioxides & $\%$ & Topsoil & 0.66 & 21.74 & $\mathbf{0 . 2 8}$ & -0.10 & -0.02 & -0.12 \\
Organic Content & $\%$ & Subsoil & 0.12 & 6 & 0.08 & -0.14 & -0.08 & 0.18 \\
Organic Content & $\%$ & Topsoil & 0.33 & 9.09 & 0.07 & 0.02 & 0.16 & $\mathbf{0 . 4 9}$ \\
pH & & Subsoil & 3.2 & 5.8 & -0.07 & $\mathbf{0 . 3 7}$ & 0.04 & -0.15 \\
pH & & Topsoil & 2.9 & 5.8 & -0.03 & $\mathbf{0 . 3 6}$ & -0.10 & -0.20 \\
Reserve Ca & ppm & Subsoil & 6 & 1296 & 0.21 & -0.07 & -0.15 & 0.01 \\
Reserve Ca & ppm & Topsoil & 1.05 & 2957 & 0.11 & 0.05 & $\mathbf{- 0 . 3 9}$ & 0.11 \\
Reserve K & ppm & Subsoil & 430 & 15294 & 0.25 & 0.01 & 0.11 & $\mathbf{- 0 . 2 9}$ \\
Reserve K & ppm & Topsoil & 95 & 10162 & $\mathbf{0 . 2 7}$ & -0.02 & -0.02 & -0.22 \\
Reserve Mg & ppm & Subsoil & 65 & 9882 & 0.19 & $\mathbf{0 . 2 7}$ & -0.02 & -0.12 \\
Reserve Mg & ppm & Topsoil & 17.92 & 7215 & 0.20 & 0.24 & -0.07 & -0.12 \\
Reserve P & ppm & Subsoil & 32 & 995 & 0.22 & -0.09 & -0.19 & 0.03
\end{tabular}




\begin{tabular}{lllllllll} 
Reserve P & ppm & Topsoil & 0.172 & 634 & 0.24 & -0.06 & -0.21 & 0.12 \\
Total N & $\%$ & Subsoil & 0.015 & 0.292 & 0.25 & -0.04 & -0.07 & 0.09 \\
Total N & $\%$ & Topsoil & 0.025 & 1.26 & 0.17 & 0.01 & 0.14 & $\mathbf{0 . 3 1}$ \\
Exchangeable Ca & me\% & Subsoil & 0.01 & 3.07 & -0.06 & 0.16 & -0.21 & 0.11 \\
Exchangeable Ca & me\% & Topsoil & 0.01 & 10.89 & -0.02 & 0.17 & $\mathbf{- 0 . 3 9}$ & 0.15 \\
Exchangeable K & me\% & Subsoil & 0.01 & 0.91 & 0.08 & 0.16 & 0.09 & 0.17 \\
Exchangeable K & me\% & Topsoil & 0.01 & 0.82 & 0.10 & 0.11 & 0.08 & $\mathbf{0 . 3 3}$ \\
Exchangeable Mg & me\% & Subsoil & 0.01 & 1.96 & 0.07 & $\mathbf{0 . 3 3}$ & -0.18 & 0.02 \\
Exchangeable Mg & me\% & Topsoil & 0.01 & 3.59 & 0.10 & $\mathbf{0 . 3 3}$ & -0.22 & 0.12 \\
Exchangeable Na & me\% & Subsoil & 0.01 & 0.27 & 0.00 & 0.25 & $\mathbf{0 . 3 2}$ & -0.09 \\
Exchangeable Na & me\% & Topsoil & 0.01 & 0.29 & 0.02 & $\mathbf{0 . 2 7}$ & $\mathbf{0 . 3 2}$ & -0.07 \\
Silt & $\%$ & Subsoil & 5.9 & 49 & $\mathbf{0 . 2 7}$ & 0.01 & 0.00 & -0.07 \\
Silt & $\%$ & Topsoil & 7.4 & 55.2 & $\mathbf{0 . 2 8}$ & 0.04 & 0.04 & 0.02 \\
\hline
\end{tabular}


Table S2. The first four principal components extracted from 30 soil variables quantified at each plot in the Central Sarawak felling and drilling datasets, together accounting for $58 \%$ of variation.

\begin{tabular}{lcccc} 
& PC1 & PC2 & PC3 & PC4 \\
\hline \hline Proportion of variance explained & 0.29 & 0.13 & 0.08 & 0.08 \\
Cumulative variance explained & 0.29 & 0.42 & 0.51 & 0.58 \\
Standard deviation & 2.97 & 1.95 & 1.59 & 1.51 \\
\hline \hline
\end{tabular}


Table S3. Type III tests of GLMM fixed effects for associations of the probability of heart rot in trees of mixed dipterocarp in Sarawak, Borneo, in each dataset. Only genera with at least two species and at least one observation with heart rot were included in analyses. No two-way interactions were statistically significant.

$\begin{array}{lrrrr}\text { Predictor variable } & \text { Num. df } & \text { Den. df } & F & p \\ \text { Felling } & 1 & 614 & 26.58 & <0.001 \\ \text { DBH } & 7 & 614 & 3.71 & 0.006 \\ \text { Genus } & & & & \\ & & & & \\ \text { Drilling } & 1 & 578 & 36.44 & <0.001 \\ \text { DBH } & 6 & 578 & 4.77 & <0.001 \\ \text { Genus } & & & & \\ \text { Coring } & & & & \\ \text { DBH } & 1 & 140 & 9.55 & 0.002 \\ \text { Genus } & 3 & 140 & 1.75 & 0.164\end{array}$


Table S4. Type III tests of GLMM fixed effects for associations of probability of hear rot in the Lambir coring dataset. No two-way or three-way interactions were statistically significant.

$\begin{array}{lrrrr}\text { Predictor variable } & \text { Num. df } & \text { Den. df } & F & p \\ \text { Model 1 } & 1 & 195 & 15.35 & <0.001 \\ \text { DBH } & 1 & 195 & 0.63 & 0.427 \\ \text { Individual wood density } & 1 & 195 & 0.04 & 0.850 \\ \text { Soil type } & & & & \\ & & & & \\ \text { Model 2 } & 1 & 196 & 16.76 & <0.001 \\ \text { DBH } & 1 & 196 & 0.26 & 0.609 \\ \text { Individual wood density } & 1 & 196 & 1.01 & 0.390 \\ \text { Soil association } & & & & \end{array}$


Table S5. Goodness of fit of models of heart rot probability and severity as measured by pseudo- $\mathrm{R}^{2}\left(p R^{2}\right)$ metrics. The marginal $p R^{2}$ is a measure of the proportion of variance in heart rot probability or severity explained by the fixed effects alone, whereas the conditional $p R^{2}$ estimates the variance explained by both the fixed and random effects. For all models, the random effect was species identity.

$\begin{array}{lcc}\text { Model } & \text { Marginal } p R^{2} & \text { Conditional } p R^{2} \\ \text { Heart rot probability } & & \\ \text { Felling model 1 } & 0.08 & 0.27 \\ \text { Felling model 2 } & 0.16 & 0.32 \\ \text { Drilling model 1 } & 0.11 & 0.38 \\ \text { Drilling model 2 } & 0.17 & 0.37 \\ \text { Coring model 1 } & 0.25 & 0.42 \\ \text { Coring model 2 } & 0.33 & 0.45 \\ \text { Heart rot severity } & & 0.18 \\ \text { Felling model 1 } & 0.02 & 0.24 \\ \text { Felling model 2 } & 0.11 & \end{array}$


Figure S1. Diagram showing the sampling design at plots within clusters, with an example of trees in and out of the plot, as judged by the prism according to angle subtended by the diameter at breast height $(\mathrm{DBH})$ and the distance from plot centre. Augered soil samples (stars) were 0-50 $\mathrm{cm}$ in depth, and the profile pit at the plot center (rectangle) was $55 \mathrm{~cm}$ deep. Auger samples were analysed as detailed in the Methods section of the main text for soil properties.

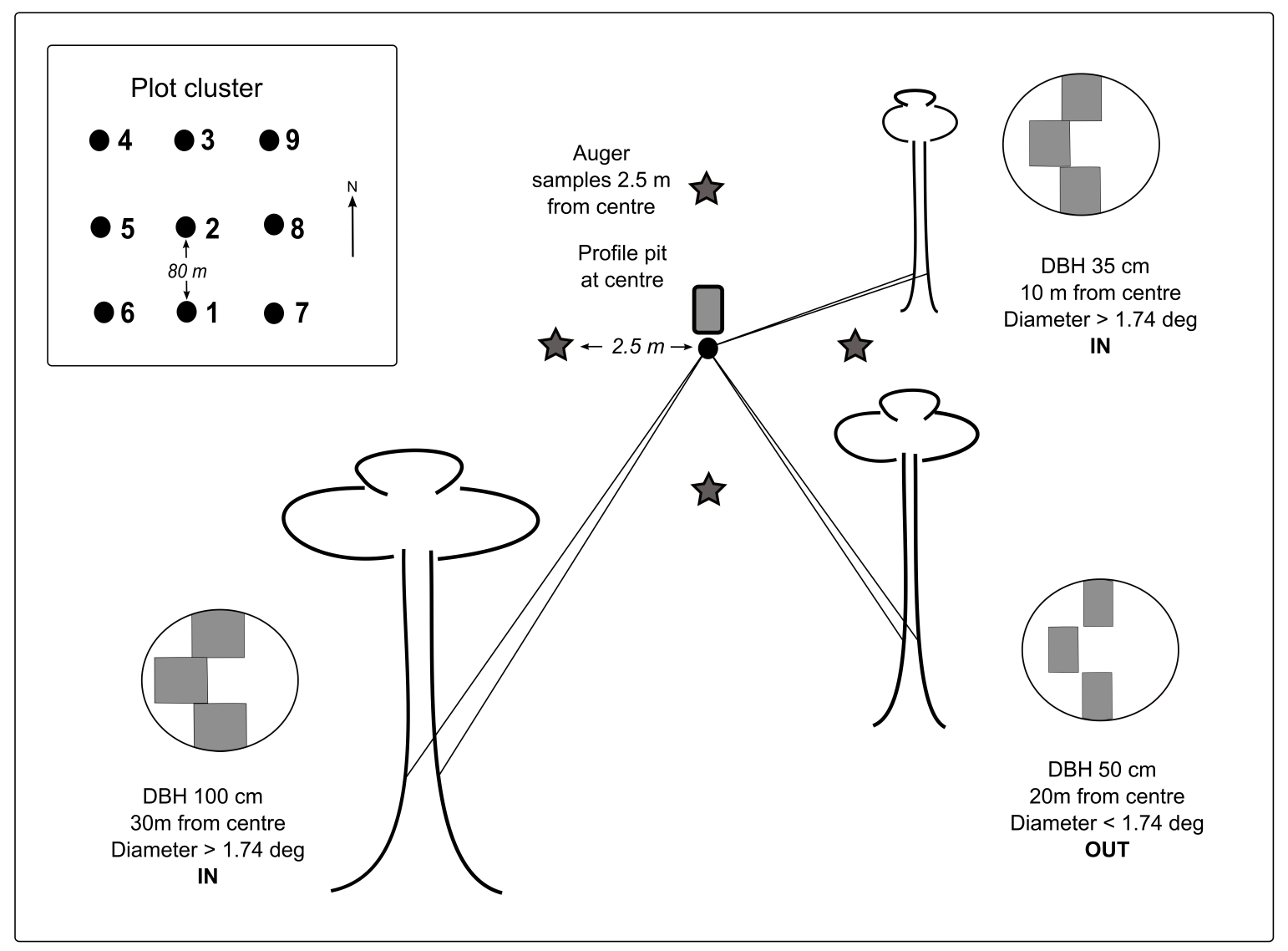


Figure S2. Historical photographs of field workers sampling for heart rot during the FIDP study, producing the Central Sarawak Drilling and Felling datasets. Photographs were taken in 1969 by Peter Sie. Clockwise from the top left, the photographs show felling of a tree, drilling of a tree (top, right), measurement of a $\log$ with heart rot (bottom, right), and measurement of a sound log (bottom left)
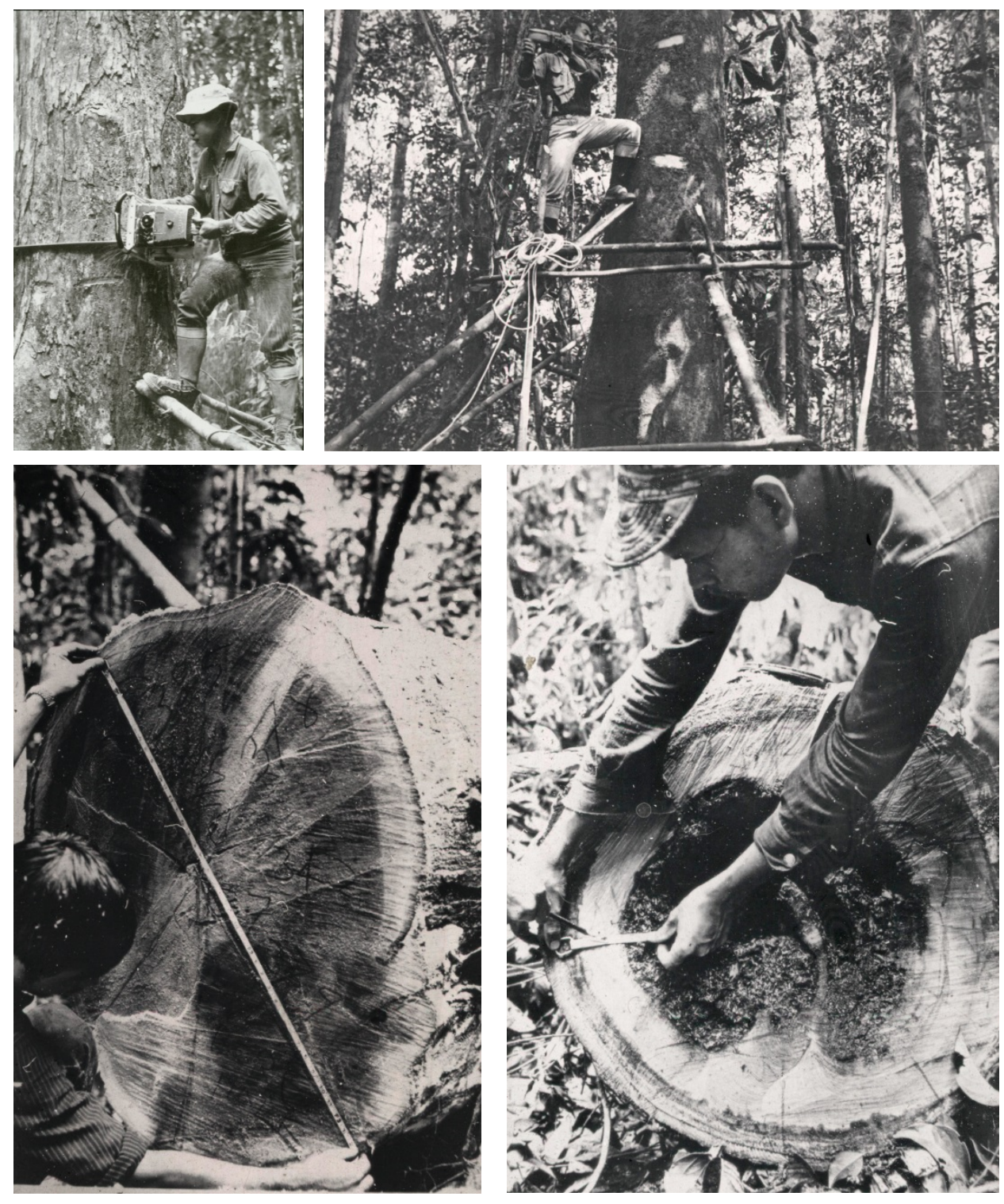
Figure S3. Boxplots showing the distributions of the first four soil principal component values (PC) for each of 36 clusters included in the analysis of the correlation of stand-level biomass lost to heart rot $\left(\right.$ Loss $\left._{\max }\right)$ with soil environmental variables.
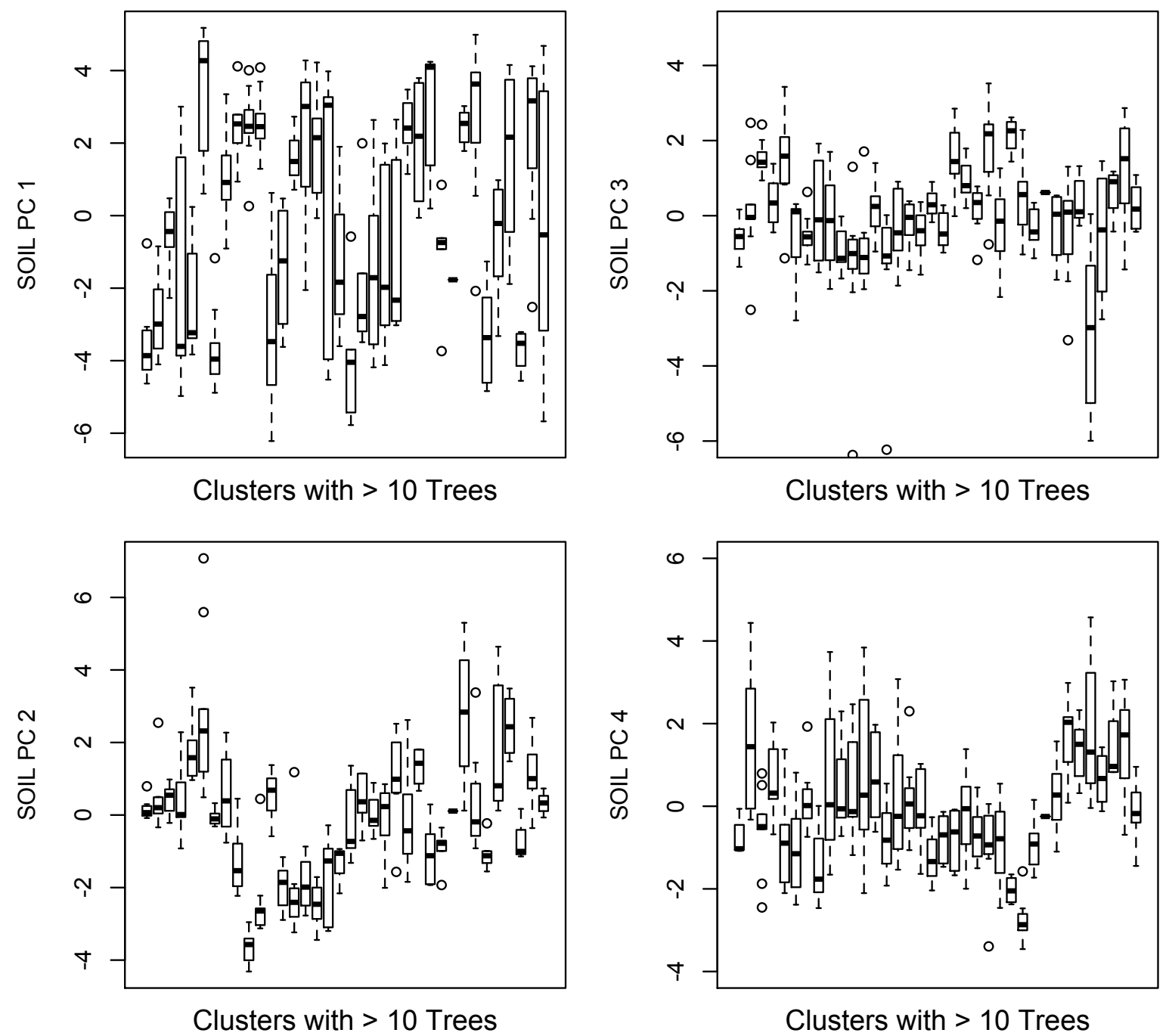
Figure S4. Variation in the probability of heart rot with tree species wood density in mixed dipterocarp rain forest of Central Sarawak, Borneo, in the drilling data. Circles are predicted values of heart rot probability based on model 1 and are scaled to increase with larger tree diameter at breast height (DBH). Ticks at the top and bottom are a rug plot showing the presence and absence, respectively, of heart rot for each tree at its wood density value and are jittered to decrease overlap. Lines show the predicted relationship between heart rot probability and wood density or mortality rate for three quartiles of DBH (light gray, 25\%; medium gray, 50\%; dark gray, 75\%), with all other predictor variables held at their mean values.

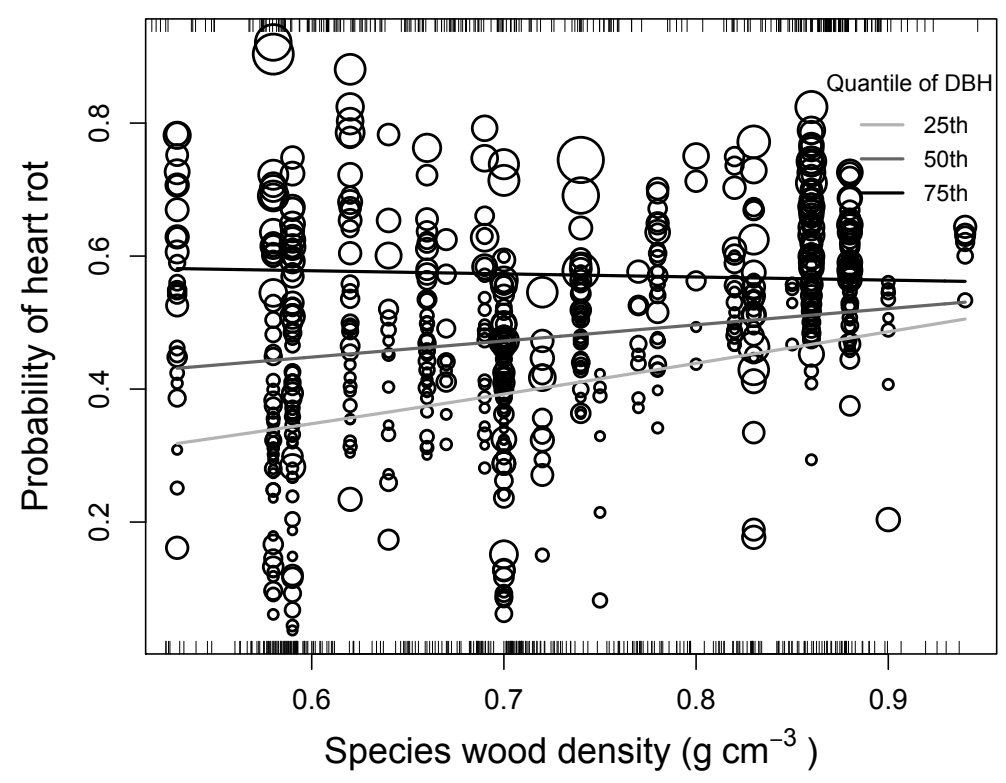


Figure S5. Variation in the predicted probability of heart rot with A) soil principle component two (PC2) in the Central Sarawak drilling data and B) principle component three (PC3) in the felling dataset. Circles are predicted values of heart rot probability based on model 1 and are scaled to increase with larger tree diameter at breast height (DBH). Ticks at the top and bottom are a rug plot showing the presence and absence, respectively, of heart rot for each tree at its soil PC value and are jittered to decrease overlap. The line shows the predicted relationship between heart rot probability and PC2 with all other predictor variables held at their mean values.
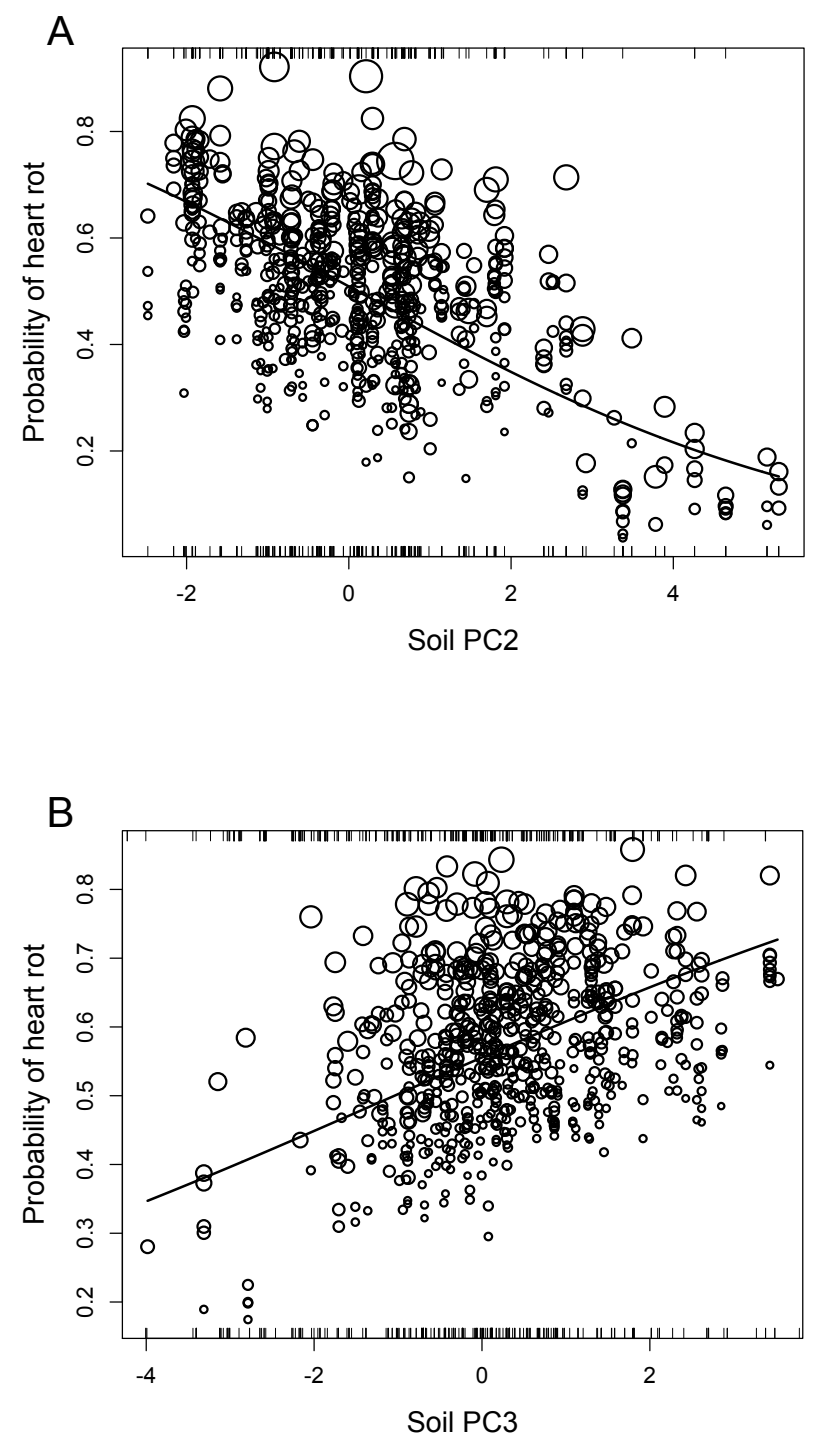
Figure S6. Variation predicted probability of heart rot for model 2 in the felling dataset. Species were categorized into four soil habitat association groups. Ticks at the top and bottom of (A) are a rug plot showing the presence and absence, respectively, of heart rot for each tree at its soil PC value and are jittered to decrease overlap.

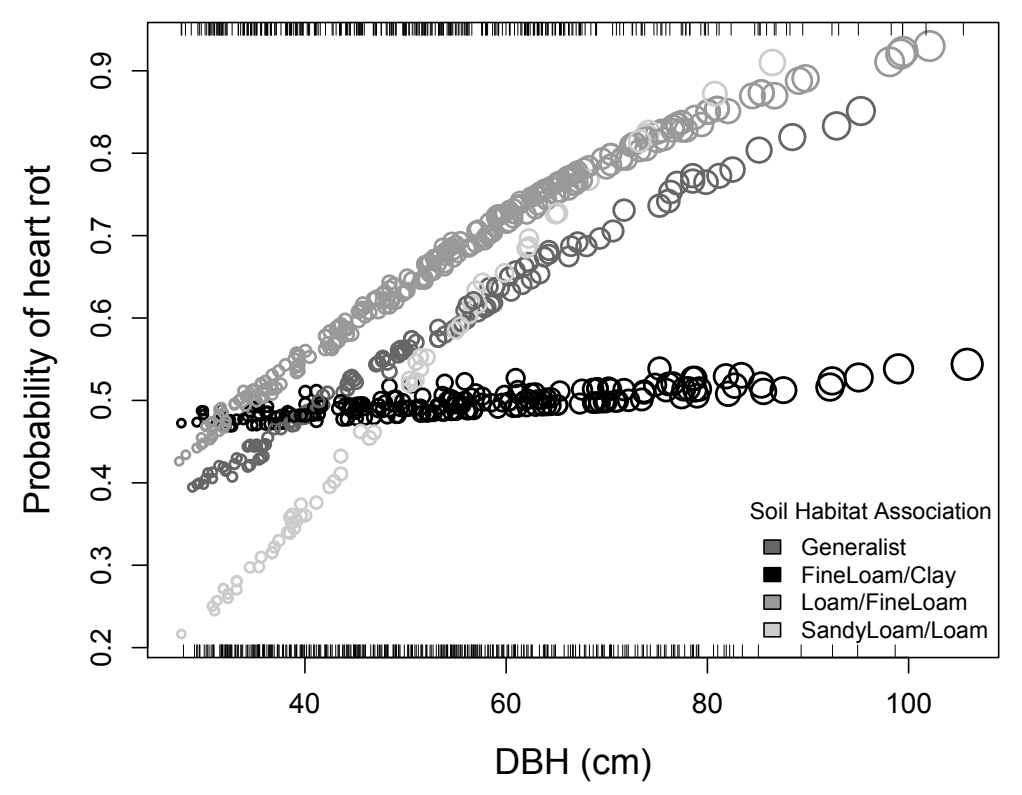

